Technical Report 1104

\title{
Platoon Readiness as a Function of Leadership, Platoon, and Company Cultures
}

Bernard M. Bass and Bruce J. Avolio

Binghamton University

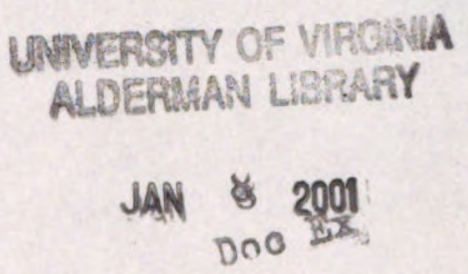

Goverevest DOCuManis

August 2000

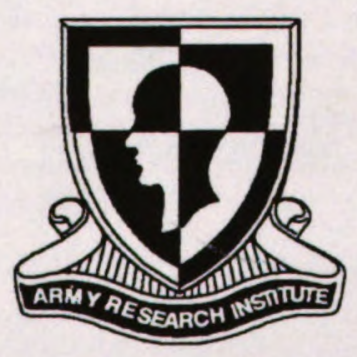

United States Army Research Institute for the Behavioral and Social Sciences

Approved for public release; distribution is unlimited.

UNIVERSITY OF VIRGINIA LIBRARY

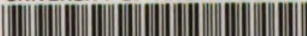

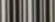

